\title{
Scholars and their books
}

\author{
K. Brad Wray ${ }^{1}$ Luciano Boschiero
}

Published online: 18 January 2018

(C) Springer Science+Business Media B.V., part of Springer Nature 2018

The job of the twenty-first century academic can be quite demanding, with many duties and obligations. We have our teaching responsibilities, our service duties to our departments, and our professional obligations. And the productive academic is often over-committed. We can forget sometimes that we are also scholars.

But every now and then when we are hosting a visiting speaker in our department or Centre, between rushing to a colloquium or introducing the speaker to our colleagues, we have a few brief somewhat relaxed moments with them in our office. Usually it is prompted by a task. We need to get a visiting speaker to sign a form so they can be reimbursed for their travel costs, or we need to give them instructions on how to get back to their hotel after their colloquium or after dinner with colleagues. It is at these times that we are reminded of the importance of our books. Even a colleague who you have met rarely or up until then only through their books and articles will be drawn to scan the books on your office shelves. It is an irresistible urge. We have been visiting speakers ourselves. We both know one cannot help oneself, that is, a scholar cannot. Looking at the shelves of books, our guest remarks on books they also have and enjoyed reading or disagreed with fiercely, books they have always wanted to read but never had the time for, and books they have never heard of before but that intrigue them. Now the conversation is usually diverted off topic. The form they need to sign is absent-mindedly placed on your desk somewhere in your own piles of work that already need sorting, or the instructions to the hotel are forgotten. The conversation begins to move around, directed by the order of the books on your shelf. They jump from topic to topic as their eyes fall

\footnotetext{
K. Brad Wray

kbwray@css.au.dk

Luciano Boschiero

1.boschiero@campion.edu.au

1 Centre for Science Studies, Aarhus University, Aarhus, Denmark

2 Campion College, Sydney, Australia
} 
upon book after book. They may even ask what principle you use to order your books, if it is not transparent to them from their initial scanning. Now you are reminded that you are a scholar. It is not only your awareness of your beloved books that remind you that you are a scholar. It is also the fellowship, the pleasure of exchanging ideas, not always agreeing of course, with another book-loving scholar. The books become an escape of sorts from the various distractions that too easily fill our daily lives. We are reminded of how broad our intellectual interests are, and how curious we are about the world. This is when we are reminded how privileged we are to be academics in the twenty-first century. The academic career provides a place for our scholarly self, and a place to meet with other scholarly sorts.

We hope that this issue of Metascience provides another reminder of your scholarly self. Even if you cannot take the time to read a book right now, perhaps a book review or two can provide sustenance until you have the time to sit down and read a book or engage with a scholarly friend. 